\title{
The Effects of an Eight Week Weight Loss Program in Obese Adults Utilizing a Nutritional Supplement
}

\author{
Gerry Lane*
}

\author{
Metabolic and Genetic Research Institute, Largo, Florida, USA
}

\begin{abstract}
A non-placebo controlled, blinded study utilizing a commercially available meal replacement (manufactured by Nutrition Laboratories Inc., Florida) studied 35 adult participants to determine the safety and efficacy of the product (a liquid nutrient concentrate) while measuring weight reduction, lipids, and adipose tissue, liver enzymes and metabolic indices (glucose, cholesterol and triglycerides) over an eight-week period. The average weight loss after 14 days was 18.2 ( \pm 3.7 ) pounds and $28.4( \pm 6.5)$ pounds at the conclusion of the eight-week trial. This was found to be statistically significant $(p<.01)$. Patient's metabolic functions were closely monitored in order to document therapeutic benefit, while monitoring for potential side effects. Total cholesterol was lowered in all participants (ave. reduction $=20.6 \mathrm{mg} / \mathrm{dL}$ ) and every participant with clinically elevated cholesterol $(\geq 200)$ at baseline, reported normal values after eight-weeks. Similarly, all participants with fasting hyperglycemia (s. glu. $\geq 100$ ) returned to normal by the end of the study. This included three patients with NIDDM who were not well controlled prior to the study. There was no evidence of hypoglycemia (s. glu. $\leq 65$ ). Participants with elevated liver enzymes at baseline reported normal SGOT \& SGPT levels after two-weeks. No participant developed liver enzyme elevations. Subjective energy level of the participants was reported at baseline as low to average and reported as high to very high at the conclusion of the study. All participants lost total adipose tissue with the average change calculated at a $6.7 \%$ loss.
\end{abstract}

Keywords: Metabolic syndrome, insulin resistance, type II diabetes mellitus, obesity, atherosclerosis, hyperlipidemia.

\section{INTRODUCTION}

Obesity is the number one contributor to the development of metabolic syndrome (obesity, diabetes mellitus, heart disease and atherosclerosis) in developed countries [1]. The toll, due to obesity, both medically and economically is huge [2]. While genetic factors contributing to obesity, hyperlipidemia and diabetes cannot be changed, we can successfully address the exogenous contribution to these disease states. Pharmaceutical attempts to promote weight loss have historically been accomplished via drastic surgical means [3] and appetite suppressants that many times are addictive $[4,5]$ and or have cardiovascular side effects [6-9]. The prescribing patterns of these medications are closely monitored by the board of pharmacy in most states, due to abuse [10] and missuse by patients and prescribers. This study was conducted to document scientifically an effective and safe product to help obese individuals lose weight. The individual components of the nutritional supplement have been studied for safety and effectiveness. The purpose of this study was to evaluate the effectiveness and safety of this proprietary blend [11] as an aid to weight loss. The results of this study bear out that there are safe, effective adjuncts to weight loss without the need for prescription medication or frequent physician visits.

*Address correspondence to this author at the Metabolic and Genetic Research Institute, Largo, Florida, USA; E-mail: ifmresearch@aol.com

\section{METHODS}

Inclusion in the study required that all subjects were obese adults, between the age 18 and 65, whose weight was at least $30 \%$ over IBW (ideal body weight see example $\left.{ }^{\star \star}\right)$. IBW for males was calculated utilizing the formula: $106 \#$ for the first 60 " of height and 6\# for each additional inch, plus or minus 6'\#s. Females utilize the formula: $100 \#$ for the first 60 " and $5 \#$ for each additional inch, plus or minus 5\#'s The study sample consisted of 35 qualified and consented subjects, 27 females and 8 males. The average percentage over IBW was $36 \%$ (range of $30 \%-45 \%$ ). All participants received a general physical exam, anthropological body measurements utilizing the Jackson - Pollock scale. This included weight, body circumference measurements of arms, abdomen, hips and thighs plus body fat analysis with caliper measurements of arms, sacroiliac and thigh in females and chest, abdomen and thigh in males. Laboratory analysis included comprehensive metabolic panel + lipids at baseline visit and upon conclusion of the study (day 56). On the first visit, the participants were started on a bowel cleanser which consisted of 3 tablets of senna (100mg) and given the study products (see list of ${ }^{* * *}$ ingredients) and protocol for days 1-56. They returned on day 3 to discuss the results of baseline laboratory. Participants were offered the opportunity to return on day 14 for a re-weight and follow up lab if they were clinically indicated. On day 56, all participants were seen for a follow up visit. Weight, body measurements and labs 
were repeated. The primary ingredients, by volume, include Opuntia ficus-indica [12-14], Aloe barbadensis miller [15, 16], Silybum marianum [17], however a complete list of active elements are located below ${ }^{* * *}$.

**IBW Examples: a male 5' 8" (68") would have an IBW of $148-160$. A female of $58^{\prime \prime}$ (68") would have an IBW of 135-145. Study participants would be equal or greater than $30 \%$ more than the upper limit of the IBW range. The male in the above example would have to weigh $\geq 208$ (30\% greater than 160$)$ and the female would have to weigh $\geq 188$ (30\% greater than 145).

\section{Statistical Analysis}

Student $t$-test was carried out on each variable to determine if there was a significant difference between the mean of the initial measurements, (baseline) and the mean of the subsequent measurements (poststudy). All results rejected a null hypothesis and were significantly different, $(p<0.05)$. The Pearson coefficient was calculated to test the degree of correlation in the change detected between the pre and post-treatments. All results showed a significant coefficient $(r=.82,67.24 \%)$ consistent with the change observed clinically.

\section{RESULTS}

All measurements reported on the 35 subjects were recorded twice during the study (at randomization [day \#1] and at the conclusion of the study, [day \#56]). A large portion of the participants $(n=27)$ voluntarily presented at day 14 to evaluate short term weight loss. The average weight loss after 14 days was $18.2( \pm 3.7)$ pounds. Statistical analysis of the two week weight loss was not performed and was considered anecdotal. It is mentioned here to note that there were short term and long term effects to the nutritional supplement. All subjects served as their own controls.

\section{Total Body Weight}

Every subject in the program lost weight. Weight loss due to bowel catharsis was an average of 2.7 ( \pm 1.3). This weight loss was discarded when evaluating the total weight loss, as it was considered fecal matter and not loss of fat mass. All participants continued to utilize the nutritional supplement program to replace one meal per day for a total of 56 days. The average weight loss after 14 days was $18.2( \pm 3.7)$ pounds and $28.4( \pm 6.5$ ) pounds at the conclusion of the 8 week trial. The eight week weight loss was found to be statistically significant $(p<.01)$.

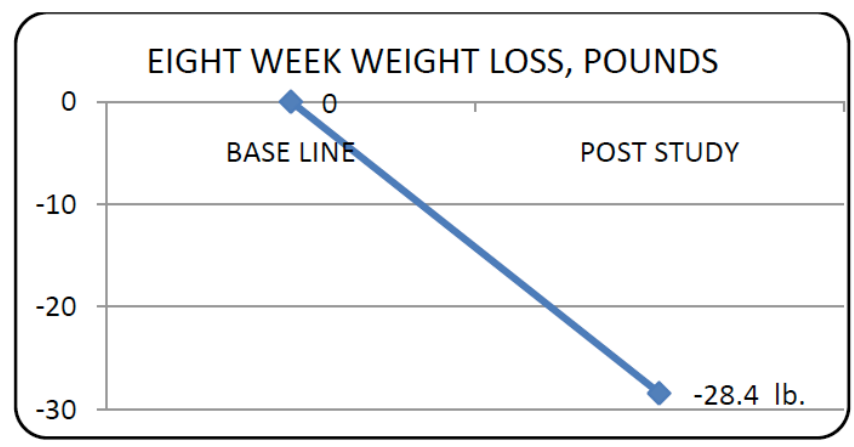

\section{Adipose Tissue}

The average percentage loss of adipose tissue was $6.8 \%( \pm 0.8),(p<0.05)$.

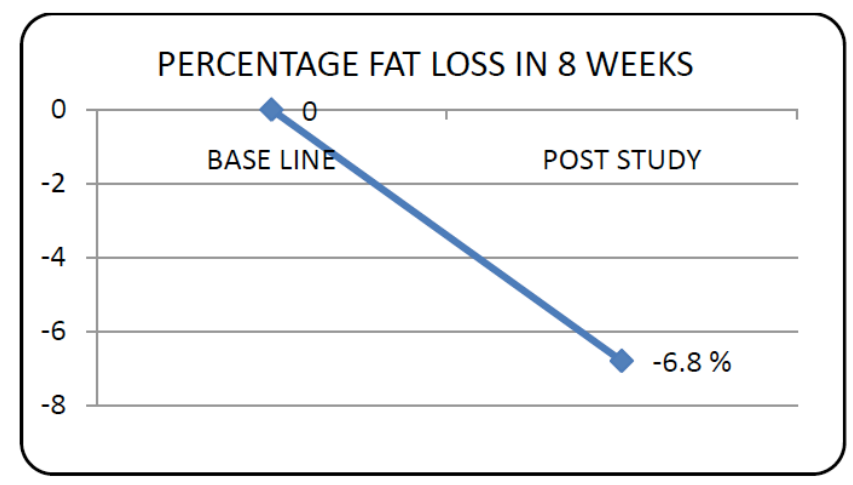

\section{Metabolic Indices}

Glucose: The average serum glucose at baseline was $93.76 \mathrm{mg} / \mathrm{dL} \pm 1.89$. Glucose at day 14 was 89.55 $( \pm 1.80)$ and $92( \pm 1.54)$ at the conclusion of eight weeks. These numbers were not statistically significant. Three participants with clinically significant hyperglycemia (fasting glucose $\geq 100$ ) had normal values at the conclusion of the study. Of these three subjects, the baseline fasting glucose was 154.33 ( \pm $22.67 \mathrm{mg} / \mathrm{dL}$ ). These three subjects fasting glucose on day 42 was $94( \pm 2.33 \mathrm{mg} / \mathrm{dL})$. $\mathrm{Hgb} \mathrm{A}_{1} \mathrm{C}$ was not obtained. These findings were not statistically significant, however, clinically very revealing.

\section{Total Cholesterol}

The average loss of total cholesterol was 20.6 $\mathrm{mg} / \mathrm{dL}( \pm 6.23)$. The total cholesterol at baseline was $192.2 \mathrm{mg} / \mathrm{dL}( \pm 8.05)$ and at day 42 , was $171.6 \mathrm{mg} / \mathrm{dL}$ $( \pm 5.67),(p<0.05)$. 


\section{Triglycerides}

The average loss in triglycerides was $18.3 \mathrm{mg} / \mathrm{dL}( \pm$ $4.22)$ for 34 of the 35 patients, $(p<0.05)$.

Of particular interest was one participant whose baseline triglyceride was $1430 \mathrm{mg} / \mathrm{dL}$ (normal $\leq 149$ $\mathrm{mg} / \mathrm{dL}$ ). The subject was notified of the "critical" values and was offered to be more closely monitored and to be referred to an independent physician for further evaluation. He initially chose to remain in the study. At day 14 his triglyceride level was reduced to $894 \mathrm{mg} / \mathrm{dL}$, at day 28 was reduced to $782 \mathrm{mg} / \mathrm{dL}$ and at day 42 was reduced to $593 \mathrm{mg} / \mathrm{dL}$. He experienced a reduction of $837 \mathrm{mg} / \mathrm{dL}$ of his triglycerides. This outlier is clinically interesting, although not considered a statistically significant. His data was excluded from the statistical analysis, as he was lost to follow-up. Upon conclusion of the study, he was advised to follow-up (via certified mail) with a physician.

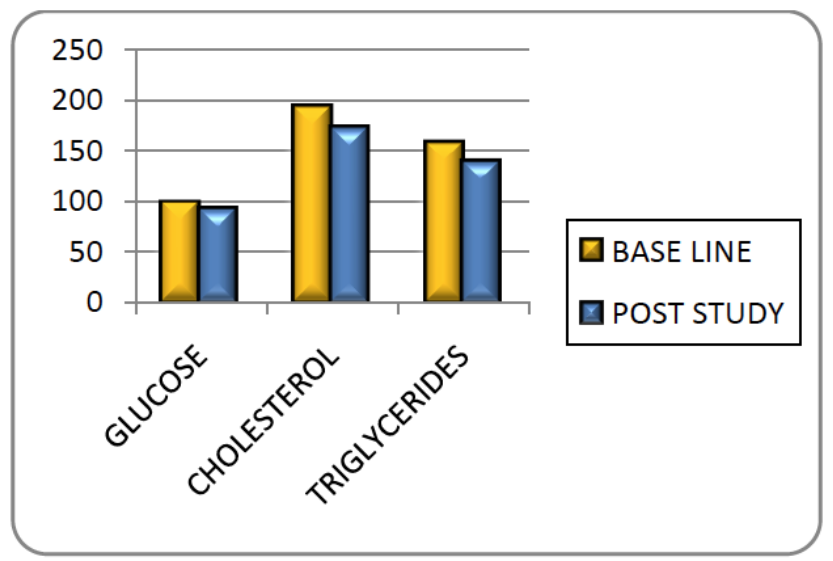

Figure 1: Metabolic indices, mg/dl.

\section{DISCUSSION}

This study was a blinded, clinical trial in which subjects served as their own control for a period of 8 weeks (56 days). The primary end points of the study were to document the efficacy of a nonpharmacological weight loss system while monitoring for safety. Secondary end points were to demonstrate if the studied products would improve the components of metabolic syndrome. This is accomplished by reducing fasting glucose, cholesterol and triglycerides while monitoring hepatic and renal functions for safety.

Each subject was monitored for changes in total body weight, percentage of adipose tissue (total body fat), waist, hips, chest measurements as well as glucose, SGOT, SGPT, albumin, total cholesterol and triglycerides.
Significant reductions were found in total weight loss, total body adipose tissue, cholesterol and triglycerides while participants experienced no clinically significant adverse effects. There were no elevations in hepatic function studies and participants experienced normalization in SGOT, SGPT if those values were elevated at baseline. Likewise, there were three participants with elevated fasting glucose at baseline. These three participants had normalization of their fasting glucose upon conclusion of the study, while there were no subjects who experienced hypoglycemia. All subjects reported stable serum albumin levels as documentation maintenance of proper nutritional balance.

\section{ACKNOWLEDGEMENT}

Dr. Lane is the Scientific Director of Metabolic and Genetic Research Institute: Largo, Florida. $\mathrm{He}$ is a graduate of Ohio University College of Osteopathic Medicine, Athens, Ohio and Past Associate Medical Director for Hilltop Research and Radiant Research, Columbus Ohio. Past Associate Professor of Medicine, Ohio University, College of Osteopathic Medicine, Dept of Family Medicine \& Geriatrics, Athens, Ohio.

Dr. Lane reports no financial affiliation with Nutrition Laboratories Inc., Florida

\section{Ingredients}

Opuntia ficus-indica [11-13], Aloe barbadensis miller [14, 15], Silybum marianum [16], Eleutherococcus senticosus [18, 19], Panax quinquefolius [20], Camellia sinensis [21], Rhodiola rosea [22], Schisandra Chinensis [23], Pfaffia paniculata [24], llex paraguariensis [25], Tabebuia avellanedae [26],Garcinia cambogia [27], Gymnema sylvestre [28], Foeniculum vulgare [29], Arctium minus [30], Mentha peperita [31], Ulmus rubra [32], Glycyrrhiza glabra [33], vitamins $A, D 3, C, B 1, B 2, B 3, B 5, B 12$, folic acid, biotin, choline, calcium, magnesium, potassium, chromium, arginine, carnitine, glutamine, isoleucine, leucine, methionine, phenylalanine, threonine, tryptophan, tyrosine, valine.

\section{REFERENCES}

[1] Prevalence of Obesity in the United States, Lawrence J. Appel, MD, MPH. JAMA 2014; 312(2): 188-189.

[2] The economic impact of obesity in the United States; Ross A Hammond, Ruth Levine, Diabetes, metabolic syndrome and obesity: targets and therapy 2010; 3: 285-295.

[3] http://obesitycoverage.com/honesty-and-divorce-afterbariatric-surgery 
[4] Phentermine hydrochloride capsules package insert (Fastin, SmithKline Beecham-US), Rev 3/98, Rec 7/98.

[5] Mazindol product monograph (Sanorex, Novartis-Canada). In: Gillis MC, editor. CPS Compendium of pharmaceuticals and specialties. 33rd ed. Ottawa: Canadian Pharmacists Association 1998; pp. 1507-8.

[6] Diethylpropion hydrochloride package insert (Tenuate and Tenuate Dospan, Merrell Pharmaceuticals-US), Rev 2/96, $\operatorname{Rec} 9 / 98$.

[7] Bostwick JM, Brown TM. A toxic reaction from combining fluoxetine and phentermine [letter]. J Clin Psychopharmacol 1996; 16(2): 189-90. http://dx.doi.org/10.1097/00004714-199604000-00012

[8] Food and Drug Administration. FDA public health advisory: reports of valvular heart disease in patients receiving concomitant fenfluramine and phentermine 1997.

[9] Cannistra LB, Davis SM, Bauman AG. Valvular heart disease associated with dexfenfluramine [letter]. N Engl J Med 1997; $337(9): 636$.

http://dx.doi.org/10.1056/NEJM199708283370912

[10] Gatch, et al. Abuse Liability Profile of Three Substituted Tryptamines. Journal of Pharmacology and Experimental Therapeutics 2011; 338(1): 280-289.

http://dx.doi.org/10.1124/jpet.111.179705

[11] http://nulabinc.com/, Nulab, Inc., 2180 Calumet Street, Clearwater, FL 33765.

[12] Tesoriere L, Butera D, Pintaudi AM, Allegra M, Livrea MA, Supplementation with cactus pear (Opuntia ficus-indica) fruit decreases oxidative stress in healthy humans: a comparative study with vitamin C. Am J Clin Nutr 2004; 80(2): 391-5.

[13] Uebelhack R, Busch R, Alt F, Beah ZH, Chong PW. Effects of cactus fiber on the excretion of dietary fat in healthy subjects: a double blind, randomized, placebo-controlled, crossover clinical investigation. Curr Ther Res Clin Exp 2014; 76: 39-44. http://dx.doi.org/10.1016/j.curtheres.2014.02.001

[14] Grube B, Chong PW, Lau KZ, Orzechowski HD. A natural fiber complex reduces body weight in the overweight and obese: a double-blind, randomized, placebo-controlled study. Obesity (Silver Spring, MD), 2013; 21(1): 58-64.

http://dx.doi.org/10.1002/oby.20244

[15] Tanaka M, Misawa E, Habara N, Nomaguchi K, Yamada M, Toida $T$, Havasawa $H$, Takase $M$, Inagake M, Higuchi R. Identification of five phytosterols from Aloe vera gel as antidiabetic compounds. Biol Pharm Bull 2006; 29(7): 1418-22. http://dx.doi.org/10.1248/bpb.29.1418

[16] Okuyr A, Can A, Akev N, Baktir G, Sutlupinar N. Effect of Aloe vera leaves on blood glucose level in type I and type II diabetic rat models. Phytother Res 2001; 15(2): 157-61. http://dx.doi.org/10.1002/ptr.719

[17] Derosa G, Romano D, D'Angelo A, Maffioli P. Berberis aristata/Silybum marianum fixed combination (Berberol(®)) effects on lipid profile in dyslipidemic patients intolerant to statins at high dosages: A randomized, placebo-controlled, clinical trial. Phytomedicine 2015; 22(2): 231-7. http://dx.doi.org/10.1016/j.phymed.2014.11.018

[18] Załuski D, Janeczko Z. Variation in phytochemicals and bioactivity of the fruits of Eleutherococcus species cultivated in Poland. Nat Prod Res 2015; 1-5.

[19] Bleakney TL. Deconstructing an adaptogen: Eleutherococcus senticosus. Holist Nurs Pract 2008; 22(4): 220-4. http://dx.doi.org/10.1097/01.HNP.0000326005.65310.7c

[20] Seon-Hee OH, Byung-Hoon L. A ginseng saponin metabolite-induced apoptosis in HepG2 cells involves a mitochondria-mediated pathway and its downstream caspase-8 activation and Bid cleavage. Toxicology and Applied Pharmacology 2004; 194(3): 221-229.

[21] Mota MA, Landim JS, Targino TS, Silva SF, Silva SL, Pereira MR. Evaluation of the anti-inflammatory and analgesic effects of green tea (Camellia sinensis) in mice. Acta Cir Bras 2015; 30(4): 242-246. http://dx.doi.org/10.1590/S0102-865020150040000002

[22] Zhong Xi Yi Jie He Xue BaoChen QG, Zeng YS, Tang JY, Qin YJ, Chen SJ, Zhong ZQ. Effects of Rhodiola rosea on body weight and intake of sucrose and water in depressive rats induced by chronic mild stress 2008; 6(9): 952-5.

[23] Pan SY, Dong H, Zhao XY, Xiang CJ, Fang HY, Fong WF, $\mathrm{Yu} Z \mathrm{ZL}$, Ko KM. Schisandrin B from Schisandra chinensis reduces hepatic lipid contents in hypercholesterolaemic mice. J Pharm Pharmacol 2008; 60(3): 399-403. http://dx.doi.org/10.1211/jpp.60.3.0017

[24] Mendes FR, Carlini EA. Brazilian plants as possible adaptogens: an ethnopharmacological survey of books edited in Brazil. J Ethnopharmacol 2007; 109(3): 493-500. http://dx.doi.org/10.1016/j.jep.2006.08.024

[25] Yoon YI, Chung M, Hwang JS, Han MS, Goo TW, Yun EY Allomyrina dichotoma (Arthropoda: Insecta) larvae confer resistance to obesity in mice fed a high-fat diet. Nutrients 2015; 7(3): 1978-91.

http://dx.doi.org/10.3390/nu7031978

[26] Lee MH, Choi HM, Hahm DH, Her E, Yang HI, Yoo MC, Kim KS. Analgesic and anti-inflammatory effects in animal models of an ethanolic extract of Taheebo, the inner bark of Tabebuia avellanedae. Mol Med Rep 2012; 6(4): 791-6. http://dx.doi.org/10.3892/mmr.2012.989

[27] Chong PW, Beah ZM, Grube B, Riede L. IQP-GC-101 reduces body weight and body fat mass: a randomized, double-blind, placebo-controlled study. Phytother Res 2014; 28(10): $1520-6$ http://dx.doi.org/10.1002/ptr.5158

[28] Astell KJ, Mathai ML, Su XQ. Plant extracts with appetite suppressing properties for body weight control: a systematic review of double blind randomized controlled clinical trials. Complement Ther Med 2013; 21(4): 407-16. http://dx.doi.org/10.1016/j.ctim.2013.05.007

[29] Picon PD, Picon RV, Costa AF, Sander GB, Amaral KM, Aboy AL, Henriques AT. Randomized clinical trial of a phytotherapic compound containing Pimpinella anisum, Foeniculum vulgare, Sambucus nigra, and Cassia augustifolia for chronic constipation. BMC Complement Altern Med 2010; 10: 17. http://dx.doi.org/10.1186/1472-6882-10-17

[30] Astell KJ, Mathai ML, Su XQ. Plant extracts with appetite suppressing properties for body weight control: a systematic review of double blind randomized controlled clinical trials. Complement Ther Med 2013; 21(4): 407-16. http://dx.doi.org/10.1016/j.ctim.2013.05.007

[31] Tayarani-Najaran Z, Talasaz-Firoozi E, Nasiri R, Jalali N, Hassanzadeh M. Antiemetic activity of volatile oil from Mentha spicata and Mentha $\times$ piperita in chemotherapyinduced nausea and vomiting. Ecancermedicalscience 2013; 7: 290.

[32] Leonard SS, Keil D, Mehlman T, Proper S, Shi X, Harris GK Essiac tea: scavenging of reactive oxygen species and effects on DNA damage. J Ethnopharmacol 2006; 103(2): 288-96. http://dx.doi.org/10.1016/j.jep.2005.09.013

[33] Kang JJ, Samad MA, Kim KS, Bae S. Comparative antiinflammatory effects of anti-arthritic herbal medicines and ibuprofen. Nat Prod Commun 2014; 9(9): 1351-6. 